\title{
The Measurement of Commitment to Work
}

\author{
Lolagene C. Coombs \\ University of Michigan
}

A methodological study using conjoint measurement analysis to determine whether there is an appropriate model for measuring commitment to work in the job-family trade-off context was conducted with 213 University of Michigan students and staff as subjects. The results indicate that there are two important dimensions that can be measured: a preference for a level of involvement in the total workchild domain and a preference for a job vs. child orientation. Based on the unfolding theory of preferential choice, a scale for each dimension was developed. The Total Involvement Level Scale places respondents on a continuum from a preference for least (IL 1) to most (IL 7) involvement; the Job vs. Child Orientation Scale ranges from greatest job orientation or commitment (JC 1) to greatest child orientation ( $\mathrm{JC} 7$ ). A field test has indicated the feasibility of the scales for use in empirical research, and protocols for easy use in large surveys are presented.

It is well recognized that behavior is not a function of a single attitude but always involves various and frequently competing attitudes. In measuring and analyzing the effects of such attitudes, it is of considerable value to disentangle their separate effects and to understand how they are combined into a joint effect on preferences or on resulting behavior. Attacks on the general measurement problem of dealing with competing attitudes working simultaneously have not yet fully exploited

This research was supported by the Ford Foundation basic grant to the Population Studies Center, University of Michigan, 1225 South University Avenue, Ann Arbor, Michigan 48109. I wish to thank the participating students and staff members, and the following instructors who made students in their classes available: J. Milholland, $R$. Freedman, K. Mason, D. Freedman, J. Knodel, and M. Melendez. Thanks are due to J. Rogers for the computer analysis and to C. Coombs for helpful comments. Reprint requests should be sent to the author. 
JOURNAL OF POPULATION

some of the recent developments in measurement theory. These developments have been discussed in a paper by Krantz and Tversky (1971) and have been used effectively in a study by Coombs et al. (1975) in which preferences for different family compositions were decomposed into the competing attitudes of a size bias and a sex bias. Further discussion of the development of these preference scales and their use in cross-cultural studies is given in L. C. Coombs (1976). The methodology of conjoint measurement has, of course, considerably more generality, and this paper gives an example of a new application of the same method to another domain which also involves competing attitudes and is relevant to population research. This is the area of commitment or preference for work outside the home, in the work-family-obligation context. We will first summarize briefly the substantive context of this application, and before presenting the data and findings will review the methodology in summary form only, because details are available in the references to the work on family composition preferences.

Interest in women's employment and how it may relate to fertility and other behavior is widespread. Although many factors are involved, one issue is the question of preference or commitment to a job or career. Space does not permit, nor is it appropriate here to do a review of the extensive literature which has been emerging over the past two decades. From the early Indianapolis work (Pratt and Whelpton, 1956), outside activities and in particular the woman's work role has been considered important for fertility behavior and much attention has been paid to how these factors interact (for example, Ridley, 1959; Clarkson et al., 1970; Sweet, 1973). Considerable research emphasis also has been placed on women's roles, how they have changed (Erskine, 1970; Mason and Bumpass, 1975; Mason et al., 1976) and how the work role relates to adjustment or satisfaction in the familial setting (Nye, 1959; Axelson, 1963; Field, 1963; Orden and Bradburn, 1969; Rappaport and Rappaport, 1969; Hall and Gordon, 1973). The concept of women's commitment to work (Weil, 1961; Sobol, 1963), or the time given to various behaviors by working and nonworking wives (Vanek, 1974) has been salient in a growing body of inquiry. All of these approaches, however, have lacked a good, direct measure for women's commitment to work in the trade-off situation that for many is inherent in the work-family context. For this reason methodological research was undertaken to de- 
termine whether a scale measure of preference for an outside job vis-à-vis children could be developed, one that would have a sound measurement-theoretic basis that would insure comparability across individuals and subgroups, and one that also would be suitable for use in large surveys.

The methodological work was done with the participation of University of Michigan students and staff members. The results discussed below show that there is a viable measurement model and that there are two independent dimensions of the workchild commitment configuration. These result in two preference scales, one a total (child plus job) involvement level, and the other a job vs. child orientation. Speaking loosely, the Total Involvement Level Scale (IL) can be thought of as the amount of 'life-space' the respondent prefers to commit to these two roles. The Job vs. Child Orientation Scale (JC) indicates the relative emphasis between the job and the child-care roles which the respondent prefers; i.e., each person has a position on a psychological continuum from a primarily job orientation to a primarily child orientation.

\section{THE MEASUREMENT MODEL}

The measurement model was developed on the basis of conjoint measurement principles. It determines the data that must be obtained for the scales, which are then derived based on unfolding theory of preferential choice. These two theoretical developments are discussed briefly below, and the way the methodological work was carried out is indicated.

\section{Conjoint Measurement}

This development in measurement theory (Krantz et al., 1971) is concerned with rules of combination, and how components are put together to make up a whole. In the present application, the components are desire for a job or career and desire for children, and conjoint measurement utilizes the individual's trade-offs between these when forced to choose. First choices tell us something, but not enough; the compromise a person will make in trading off changes in one variable for changes in another can provide very useful information. It is easy, for example, to say you want a wife (or husband) who is 
good-looking, intelligent, and rich. But if you have to give up some of one thing to get another-What will your trade-off be? This tells a great deal more about a person's values than does a single stated preference. For many women there may be a trade-off in terms of work commitment and child care. The analysis of such situations is what is involved in conjoint measurement. It permits the testing of rules of combination of underlying variables, such as, in this case, a preference for work outside the home and a preference for children. Such rules of combination are really theories of how people think about the combined tasks of work and child-rearing, how they put them together to make a whole, and hence conjoint measurement provides a useful framework for analyzing and measuring the structure of their preferences. It utilizes factorial designs to test rules of combination without having to measure the variables first. The measures grow out of the theory or the model found to be appropriate in the data. It requires only ordinal relations on the dependent variable in the cells of the factorial design, and hence is useful for the types of subjective variables with which we are concerned here.

In determining how variables combine to produce a composite effect, it is important to know whether the contributions each makes to the dependent variable (in this case the preference ordering for the job and children combinations) are independent of each other. If they are, then one can be measured without having to specify the level of the other, a very useful feature for both theoretical and applied work. To be independent, the ordering of the dependent (or composite) variable must be the same in the rows or columns of the matrix, regardless of the level fixed for the contributing variables. For example, in one possible model in this application, the rows may represent the number of children, the columns the job levels, and the cell entries the preference order for the various combinations. For these two contributing variables to be independent, the ordering of preference in the rows must be the same for each row. When we find a measurement model in which these conditions obtain, we then know that those variables are independent of each other (in a measurement sense) and we also know what data must be obtained to develop measures of these variables. The following application provides a new example of how the conjoint measurement method can be used. 


\section{The Sample and Procedures}

In the methodological testing done to develop measures of attitude toward work competing with child preference, data were collected from 213 University of Michigan students and staff, largely from classes in population, psychology, history, and economics. Both graduates and undergraduates were included. While certainly not a cross-section sample, there is considerable variation in age (17-55 years; about $50 \%$ over 21$)$, marital status ( 24 percent married), sex ( 74 percent female), and family cycle stage (0-4 children; 82 percent had none). Educational and income levels varied less, although there were considerable differences among the staff members participating.

Such small convenience samples are not suitable for substantive analysis, but they are useful for methodological research. As long as the question at issue is whether some subjective variable such as work commitment can be measured and, if so, what the appropriate measurement model should be, the usual socio-demographic variables are of less concern. The psychological measurement aspects probably vary little from group to group. The fact that the model found to have the best data fit was also the best fit for each of the various subgroups gives confidence as to its application in cross-section studies. Nevertheless, if the work commitment scales were to be applied in a non-Western setting, particularly those where a job vs. child trade-off might not be a reasonable concept, it would be highly desirable to test to see if the same measurement model applied. This would be true of the measurement of any social-psychological variable; what constitutes a scale or an adequate measure in one culture may not do so in another.

To obtain the basic data for determining the appropriate measurement model, the subjects were asked to rank order a set of 16 cards. Each one presented one of the combinations ( 0 children, full time job) from the 16 possible from all combinations of $0,1,2$, or 3 children and 0 , one-half, three-quarters or full time job. These appeared to be reasonable ranges for the U.S. culture. The women were asked to respond in terms of their own preferences. The men were asked about what they would like their wives-present or future-to do. The scenario said to assume that the children were under ten years of age, and that the job was for pay outside the home. The rows and columns of the matrices obtained from these preference orderings were 
then tested for independence as described briefly above, to see which measurement model, if any, would apply. In other words, we want to determine how the subjects put together the two issues, how many children and how much of a job commitment, to obtain their overall preference ordering in these trade-off situations.

\section{Model Testing}

A number of models were tested. Each employs a different way of combining preferences for children and work, and in these combinations in fact create new variables which may not have been obvious on an a priori basis. The simplest possibility was that the subjects had a separate preference for children (C) and for a job (J) commitment that added together to make a preference for the combination, the $C$ by J model. It quickly became apparent that this was not the most appropriate model; the two preferences cannot be obtained separately and simply added together. For the $\mathrm{C}$ by J model, 30 percent passed the test for independence of $C$ with respect to J; for J with respect to $C$, the figure was 18 percent; that is, 30 percent of the respondents had the same ordering on every row of the matrix, and 18 percent had the same ordering on every column. This requirement is very demanding. To allow for a small margin of human error in card sorting, two contiguous reversals of order were permitted. For example, if reversing a 13 th and 14 th choice and reversing a fifth and sixth choice makes the rows and columns have the proper ordering to indicate independence, the model was viewed as fitting. With such allowance, the percentages fitting the $C$ by J model are raised to 38 and 27 (Table 1). The question of how good the model fit should be is moot; in fact, it is rarely addressed in most empirical work. Our interpretation is fairly stringent, and it seemed clear that a better fit than that afforded by the $\mathrm{C}$ and J model was needed.

The answer to the question of model fit is also contingent on the quality of alternative models. Another possible model that could be tested was whether respondents have a preference for a level of work commitment and also a preference for a combined job and child commitment level. As seen in the bottom panel of Table 1 , this $\mathrm{J}$ by $(\mathrm{C}+\mathrm{J})$ model is a poorer fit than the $\mathrm{C}$ by J model. The parallel model that there is a preference for children and a preference for a combined job and child com- 
Table 1. Tests for Three

Measurement Models

\begin{tabular}{|c|c|c|c|c|c|}
\hline \multirow[t]{2}{*}{ Mode1 } & \multicolumn{5}{|c|}{ Percent fitting with allowable error ${ }^{b}$} \\
\hline & Total & $\begin{array}{c}\text { Not } \\
\text { Married }\end{array}$ & Married & $\begin{array}{c}\text { No } \\
\text { Children }\end{array}$ & $\begin{array}{c}\text { Some } \\
\text { Children }\end{array}$ \\
\hline $\begin{array}{l}\frac{(\mathrm{C}+\mathrm{J}) \text { by }(\mathrm{C}-\mathrm{J})}{\text { Independence }} \text { of } \\
(\mathrm{C}+\mathrm{J}) ;(\mathrm{C}-\mathrm{J})^{\mathrm{a}} \\
(\mathrm{C}-\mathrm{J}) ;(\mathrm{C}+\mathrm{J})\end{array}$ & $\begin{array}{l}48 \\
47\end{array}$ & $\begin{array}{l}49 \\
48\end{array}$ & $\begin{array}{l}46 \\
44\end{array}$ & $\begin{array}{l}47 \\
47\end{array}$ & $\begin{array}{l}57 \\
46\end{array}$ \\
\hline 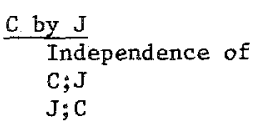 & $\begin{array}{l}38 \\
27\end{array}$ & $\begin{array}{l}37 \\
27\end{array}$ & $\begin{array}{l}41 \\
24\end{array}$ & $\begin{array}{l}36 \\
28\end{array}$ & $\begin{array}{l}50 \\
21\end{array}$ \\
\hline $\begin{array}{l}\frac{J \text { by }(C+J)}{\text { Independence of }} \\
\begin{array}{l}J ;(C+J) \\
(C+J) ; J\end{array}\end{array}$ & $\begin{array}{l}33 \\
28\end{array}$ & $\begin{array}{l}35 \\
28\end{array}$ & $\begin{array}{l}27 \\
27\end{array}$ & $\begin{array}{l}31 \\
26\end{array}$ & $\begin{array}{l}43 \\
36\end{array}$ \\
\hline Number of cases & 213 & 172 & 41 & 185 & 28 \\
\hline
\end{tabular}

mitment level was also tested, with similar results; but since such a model would yield no measure of work commitment, it is not a useful one in this context. While a measure of preference for children is of great interest, a better measure, and one that is independent of sex composition, is available elsewhere (Coombs et al., 1975).

Another alternative model hypothesizes that respondents are concerned with and have a preference regarding their level of commitment to the whole area of carrying a job and raising children, and they also have preferences about the balance or emphasis on one or the other of these activities. This, in fact, is the model with the best data fit, and it yields the two dimensions mentioned earler, a preference for a total level of involvement in the child and job domain, and a preference on a job vs. child orientation. This is the $(C+J)$ by $(C-J)$ model, which fits 48 percent of the respondents for the independence of $(C+J)$ with respect to $(C-J)$, and 47 percent on independence of $(C-J)$ with respect to $(C+J)$, including error allowance. While there is 
stronger support for this model as compared to any of the others, there is inherent interaction of the two variables for many respondents. In this complex domain of child rearing and work trade-offs there simply may be interactions which cannot be eliminated. How serious an issue this is depends in part on the purpose of the research for which the measures are to be used. The limitations are greater for basic theory building than they are in practical applications where individual scale values, their correlates, and predictive uses are the main research emphases.

Since, relative to alternative models, a higher proportion of the respondents pass the tests for independence, the $(\mathrm{C}+\mathrm{J})$ by $(\mathrm{C}-\mathrm{J})$ model is the best to use in measuring work commitment in the job-child context. Further confidence in the appropriateness of this model is gained from a two-phase strategy in the collection of data, using the same procedures but from different subjects and in different months. The results of the two phases are very similar, not only for the groups as a whole but for individual sub-groups. The ordering of model fit is the same for both phases, with the $(\mathrm{C}+\mathrm{J})$ by $(\mathrm{C}-\mathrm{J})$ model clearly the best.

\section{THE SCALE DEVELOPMENT}

Having determined the appropriate measurement model and hence the appropriate variables to measure, we then know exactly what data are needed to construct the scale measures for these two dimensions. If for convenience we reorder the appropriate but more complicated $(\mathrm{C}+\mathrm{J})$ by $(\mathrm{C}-\mathrm{J})$ matrix to the $4 \times 4$ children by job form in which the data are collected, the required data are the preference orderings on the two major diagonals of the matrix. In theory, any diagonal array could be used, but the major ones give more information and hence are preferable. With children as the rows and jobs as the columns of the matrix, the preference order indicated on the major diagonal from upper left to lower right provides the data for the Total Involvement Level Scale (IL), and the diagonal from the upper right to the lower left provides the data for the Job vs. Child Orientation Scale (JC). As discussed later, this means that a short interview form obtaining only these data can be used for large scale surveys and the scale values can be precoded in the questionnaire. The theoretical background on which the scales are based is discussed briefly in the following section. 


\section{Theoretical Basis of the Scales}

Unfolding analysis involves both a theory about the nature of the judgment process in preferential choice behavior (a theory that is empirically testable) and a technique for obtaining preference scales. Detailed discussion of the theory is given elsewhere (see Coombs, 1964; Dawes, 1972; Runkel and McGrath, 1972), but the basic ideas can be stated briefly here. The theory is based on the hypothesis that there is a subjective continuum ( $\mathrm{x}$ ) mediating an individual's choices among a given set of alternatives, in this case the possible choices of varying family and job combinations. Briefly, it is assumed that an individual has an ideal point, what he likes best, and that his preference falls off as $x$ either increases or decreases in relation to his ideal. Such a preference function is called a single-peaked utility function. An individual prefers one alternative to another if and only if it has a higher utility for him. The peak is the point of highest utility and is at the ideal. It is as though the $x$-axis were picked up or 'folded' at the ideal point or peak, and the successive choices on either side meshed into a single simple order, which is the rank order of preferences, which then must be 'unfolded' to obtain the underlying scale position; hence the name, unfolding theory.

The condition that preference orders be single-peaked in order to apply unfolding theory is a testable condition. Table 2 reports the test results for the $(C+\jmath)$ by $(C-J)$ model. Because

Table 2. Single Peakedness Test

Results for $(\mathrm{C}+\mathrm{J})$ by $(\mathrm{C}-\mathrm{J})$ Model

\begin{tabular}{|c|c|c|}
\hline & \multicolumn{2}{|c|}{ Percent Single-Peaked $^{a}$} \\
\hline & $\mathrm{C}+\mathrm{J}$ & $\mathrm{C}-\mathrm{J}$ \\
\hline Total Sample & 90 & 83 \\
\hline Not Married & 90 & 80 \\
\hline Married & 93 & 93 \\
\hline No Ch $11 \mathrm{dren}$ & 89 & 81 \\
\hline Some Children & 96 & 93 \\
\hline Under 22 Years & 90 & 81 \\
\hline 22. Years and older & 90 & 85 \\
\hline Number of Cases & 213 & 213 \\
\hline
\end{tabular}

${ }^{a}$ Without error 
the proportion single-peaked is so high, not only for the sample as a whole but for the several subgroups examined, no calculations that included an allowable error margin were made. The single-peakedness criterion employed requires that every diagonal have a single-peaked preference order pattern. Since only the major diagonals are used for the scales, however, the percent yielding usable, that is, single-peaked, scales is somewhat higher-95 and 85 percent for the IL Scale and the JC Scale, respectively.

If single-peakedness is satisfied (as has been demonstrated in these data), then the individual preference orders can be unfolded to yield a scale, conventionally called an I-scale number. This places each individual on a psychological continuum, in an interval that corresponds uniquely to his utility for $x$ as reflected in his preference order.

The principles and technique of scale development through unfolding theory can be illustrated very simply in the context of family size preferences. Although more awkward to verbalize, the same principles apply to scaling the preference orders of the job and child combinations. Let us assume that we have obtained through an interview the respondent's rank order of preferences, say, for simplicity, over the set of alternatives $0,1,2$, or 3 children. The range of these four options can be divided by the six midpoints between them, producing seven intervals, as illustrated in the top line of Figure 1. The particular distances between the four levels shown in the figure are illustrative only and are spaced so that all the midpoints can be seen clearly in the diagram. The symbol $0 \mid 1$ indicates the midpoint between 0 and 1 child, $0 \mid 2$ is the midpoint, equidistant between 0 and 2 children, etc. Although the midpoints are not given a value or used statistically in any numerical scale developed, the concept is crucial to explain the derivation of a preference order. A midpoint may be thought of, not as a statistical construct, but as the psychological dividing line on the subjective scale between preferring one choice over another. In other terminology, the midpoint is the one at which the utility for one choice becomes greater than the utility for the other. The six midpoints seen in Figure 1 divide the scale into seven intervals. Proceeding from left to right, the position of a person in a particular interval on the scale is determined by the midpoints he has 'crossed' from the left in ordering his preferences.

For each interval there is a corresponding preference order, 


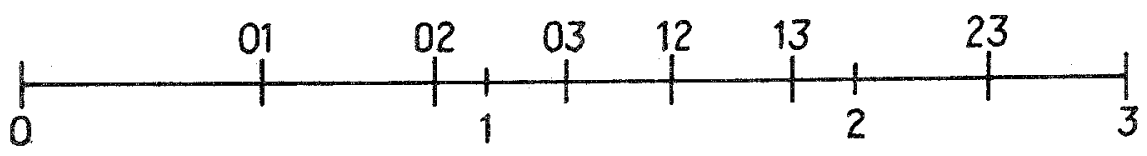

MIDPOINTS

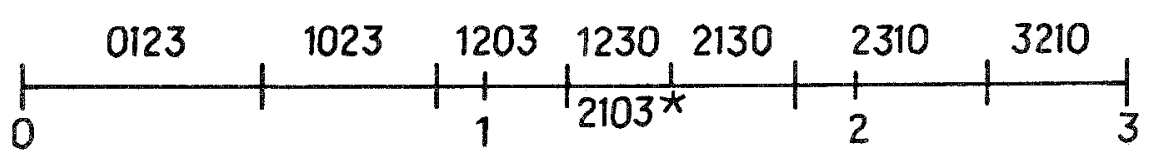

I SCALE PREFERENCE ORDERS

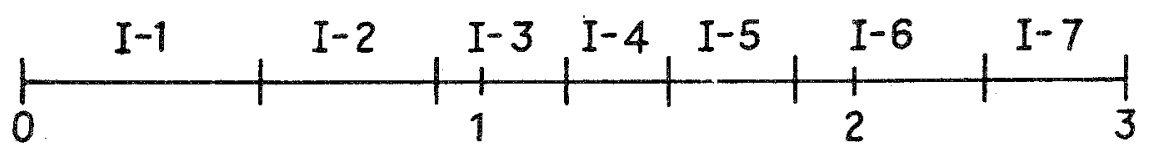

I SCALE NUMBERS

* There are two preference orders which correspond to the fourth interval on the scale. They reflect a difference in metric relations, useful for some purpose.

FIGURE 1. Relation of Preference Orders to I-Scale Numbers.

as indicated in the second line of the figure, and to be in a particular interval an individual must have a preference order that corresponds only to that interval. This is not arbitrary but is dependent on the midpoints he has crossed. For example, a person whose preference order is 0123 is on the extreme left of the scale because $1-1$, as he prefers 0 children to all other choices, he has not 'crossed' any midpoint. A person with a preference order 1203 has psychologically 'crossed' the midpoint $0 \mid 1$ (he prefers 1 to 0 ) and the $0 / 2$ midpoint (he prefers 2 to 0 ), but not the $0 / 3$ (he prefers 0 to 3 ). This set of choices places him in the 13 interval of the scale (bottom line). Thus it is seen that the I scale number or position is determined not only by a first choice but by his ordering of the other 
alternatives. A person who prefers 2 children, for example, but would rather have 0 than 3 , is quite different psychologically from one who also prefers 2 but would rather have 3 children than 0 . These differences can be important for behavior and the scales, based on unfolding theory, take them into account.

\section{The Work Commitment Scales}

When the preference orders on the two major diagonals of the job-child combination matrix are unfolded, the data yield a seven-point scale on each of two dimensions, one called the Total Involvement Level Scale and the other the Job vs. Child Orientation Scale. They range, respectively, from a preference for least (IL 1) to most (IL 7) involvement in the total child and job domain, and from greatest preference for a job (JC 1) to greatest preference for children (JC 7) in the job vs. child orientation domain.

Figure 2 shows the distributions obtained for the methodological sample yielding scalable data. While not representative of the general population, or in fact even of University of Michigan students, they are nevertheless of some substantive interest. In the first place, the preferred level of total involvement in the job and child domain is fairly high. Two thirds are IL 5 or higher, and about a fourth are in the moderate position (IL 4). Only 14 percent are IL $1-3$, indicating a preference for a rather low involvement level. Eight percent are at the lowest scale position, IL 1. They evidently prefer a life which involves little commitment to either work or children. Whether this means greater preference for involvement in other things or a general low level of life involvement cannot be inferred from these data. But it is a question of considerable substantive research interest and one for which the new measurement tool should be useful.

On the Job vs. Child Orientation Scale, about 40 percent of this (mainly student) sample are in the job emphasis end of the continuum (JC 1-3), 36 percent have a preference for greater child empahsis (JC 5-7), and about a fourth are in between (JC 4). Those in the job end of the scale, however, tend to be at the extreme end (JC 1), indicating a very strong preference for the job role, whereas those in the child end of the scale are less likely to have extreme positions. The implication of the scale position is that those who are JC 1 would choose no children at all if they had to make a job vs. child choice, whereas those who are JC 7 

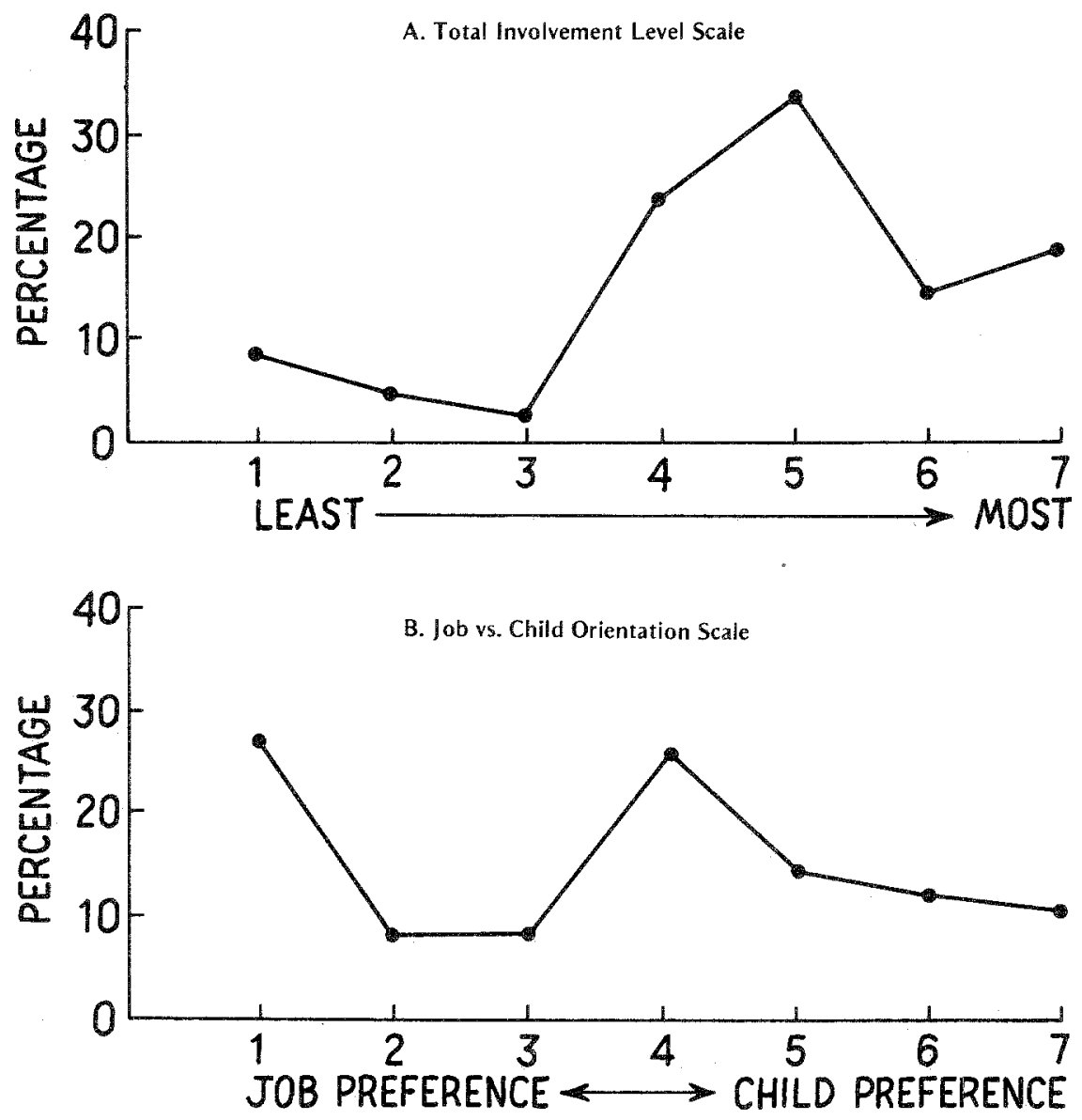

FIGURE 2. Distributions on Involvement Level Scale and Job vs. Child Orientation Scale.

would choose to do without a job, if forced to make a choice. The positions in between represent an intermediate preference or bias toward one or the other.

There are some interesting subgroup differences on the $\mathrm{JC}$ scale (data not shown). The women in this sample are more joboriented than the men preferred for their wives. This is particularly true of women over 21 years. About a third of that group is $J C 1$, compared to a fifth of the younger women. The more extreme job preference for the over 21 year olds probably reflects differences between graduate and undergraduate 
students rather than any cohort or generational changes taking place. The unmarried are more likely than others to be in the high involvement level of the IL continuum, and to be considerably more extreme in job orientation.

\section{Dominance}

Since these two measures are reasonably independent of each other in the sense that the level of preference for one is not contingent on the level of preference of the other, we find a considerable range of $\mathrm{JC}$ scale values for each $\mathrm{IL}$ scale level. For example, we see in Table 3 that there are some respondents who prefer a low total level of commitment (IL 1) but who have either extreme job or child orientations (JC 1 or JC 7). For these, the question of the relative strength of the two factors may be important. Their relative importance may be indicated by the persistence of a preference for the level of one factor as the level of the other changes. We may say that if the preference for the level of one variable persists while the level of the other factor changes, then the former dominates the latter. In these terms, we find that for 21 percent IL dominates and for only eight percent does JC dominate. (This is a statistical, not theoretical,

Table 3. Relation Between Total Involvement Level

Preference and Job vs. Child Orientation

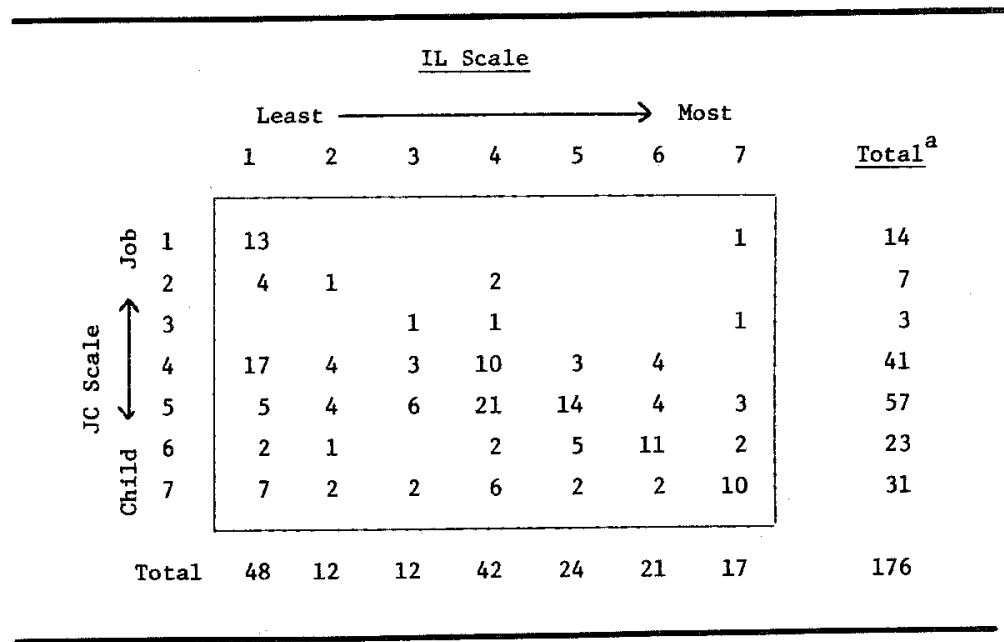

ancludes only respondents scalable on both variables. 
determination based on the first three choices.) So the total level of involvement seems more important than the job vs. child orientation for about a fifth of this sample.

For the majority, however, the dominance patterns shift from choice to choice and tend to balance out. The dominance pattern varies somewhat among the subgroups. For the younger, the females, the unmarried, and for those with no children, IL is more likely to dominate. It is of interest that, for the married women with children, JC is more likely to dominate. We should remember that, in this special sample, most of the respondents in this category are working women on the University of Michigan staff. In fact, the logic in these findings provides some corroboration of the idea that the scales are measuring something that has real meaning for the respondents.

\section{USE IN LARGE SURVEYS}

When many respondents are to be interviewed, it is desirable to have a method of data collection that is simpler and less time-consuming than the ordering of choices among 16 possible combinations. Because the measurement model determines precisely which data are needed to obtain the scales, a more parsimonious procedure is possible. Only the data for the major diagonals of the matrix need to be collected. The choice of questions is not arbitrary, but is dictated by the measurement model. The data collection could be done in several ways. Respondents could be asked to order two sets of four cards, each containing a combination from the appropriate diagonal. This is simply done, but raises the possibility of some unscalable data (if the order of the four cards is not single-peaked), and requires that the interviewer make sure the orderings are correctly recorded and that the researcher develop the scales from the orderings. Although the latter can be done through a conversion scheme, rather than going through the longer unfolding process, nevertheless, it adds another step to the procedure.

Another possible format is verbal, to obtain the data from a short series of questions asking the respondents to choose between successive pairs of combinations. This procedure has several advantages. Because single-peakedness is so commonly found in unidimensional choice behavior, the question series 
can be, and has been, devised so that all respondents who complete the choices provide scalable data (Figures 3 and 4). Further, the responses are recorded during the questioning and the possibility of error is reduced. In addition, it is possible to precode the scale values directly on the questionnaire, saving considerable coding time and possible error. Finally, because many respondents need be asked only one or two questions (depending on the response to the first questions in the series), the protocols are quickly administered in the field.

The verbal procedure can be assisted through the use of cards, so respondents can see the initial choices to be made (Figure 5). This has been found to be an advantage in practice, because it is easier to keep the alternatives in mind when making the first choice among the four possibilities. After some preliminary testing, the protocols and accompanying illustrative cards included in this report have been found to work well in the field, although this does not preclude using other procedures if thought desirable by the researcher.

It is obvious from the earlier model testing discussion that the selection of questions for the protocols is not arbitrary; it is dictated by the measurement model that has been found to apply. Other models would require different questions and, conversely, different questions would imply a different, and probably untested, measurement model. In other words the substance, though not the form, of the questions is fixed and should not be changed if valid scale measures are to be obtained.

The analytic possibilities in using the work commitment scales have not yet been explored; their development is too recent. Field feasibility has been tested, however, in an inter-

Total Involvement Level

Scale Card (blue)

(A) 0 children, no job

(B) 1 child, $1 / 2$ time job

(C) 2 children, 3/4 time job

(D) 3 children, full time job
Job vs. Child Orientation Scale Card (green)

(A) 0 children, full time job

(B) 1 child, 3/4 time job

(C) 2 children, 1/2 time job

(D) 3 children, no job

FIGURE 3. Protocols for Total Involvement Level Scale. 
[A little earlier we talked about some job and children possibilities--which you liked best, next best, and so on.] Now let me ask you about some comblnations that are a 1ittle different.

If you could have fust what you wanted, which of these would you most like (for your wife)* to have? Again, assume that the job is for pay and that the children are under 10 years of age.

Interviewer: Show respondent the green card (JC Scale). Check re-
sponse in appropriate box on first line below. If either choice A
or D is given, proceed to $Q$. If $\mathrm{B}$ or $\mathrm{C}$ is given, proceed with
the verbal questioning following arrows as indicated below.
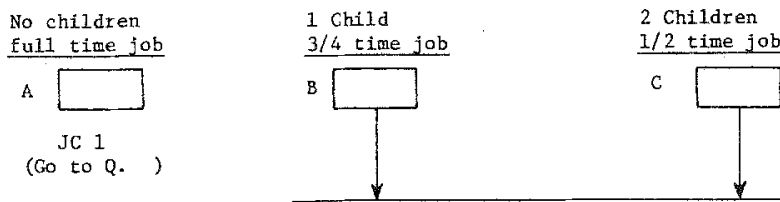

3 Children no job

,

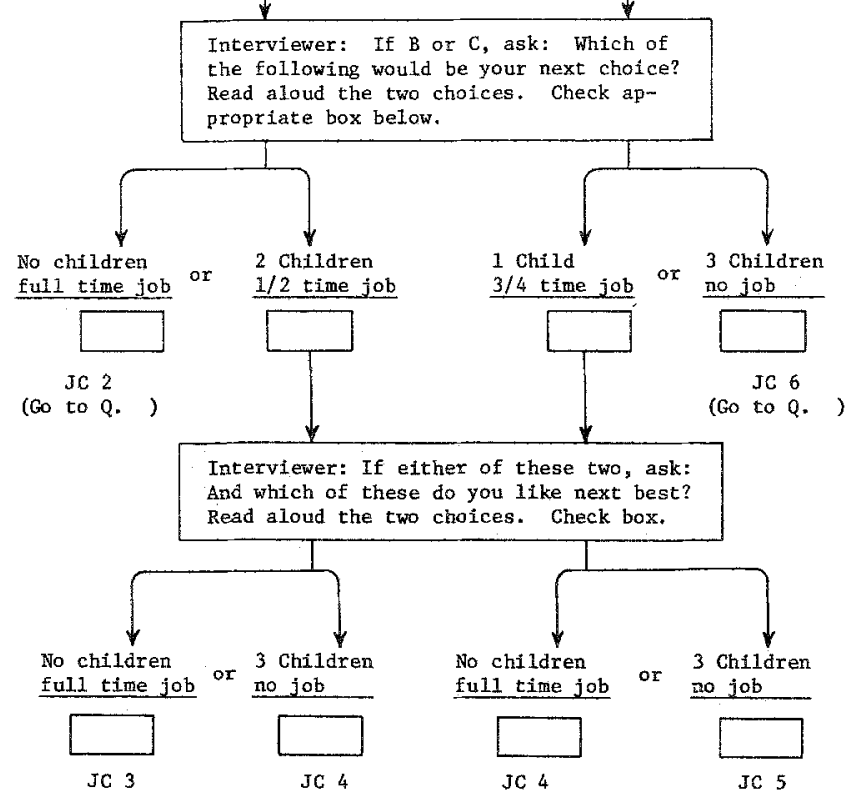

For males.

The JCH under the last box checked is the Job-Child Orientation Scale number to be coded.

FIGURE 4. Protocols for Job vs. Child Orientation Scale.

esting study on career plans among high school students in New York City being conducted by Dr. Carol Tittle of City University of New York, under the sponsorship of the National Institute for Education. The work commitment scales are included along with a number of other preference indicators, although in developing the scales their use for mature female respondents was the 
Most people have thought about possibly having children some day. Some feel there are conflicts between working at a job and having children; others do not feel this way. We want to find out how you feel about various job and child care possibilities, just what you think you would like (for your wife)* (if you get married). If you could have things just the way you wanted then, which of these four choices would you like the best?

Assume that the job is for pay outside the home and that the children are under 10 years of age.

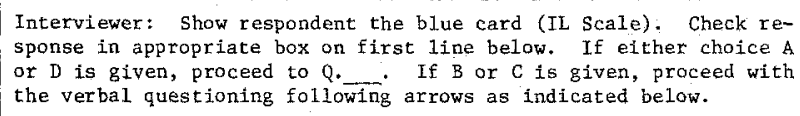

No children

no job

A

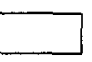

IL 1

(Go to Q. ) the verbal questioning following arrows as indicated below.

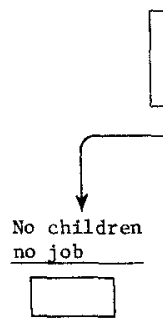

IL 2

(Go to $\mathrm{Q}$. )
1 Child

1/2 time job

B

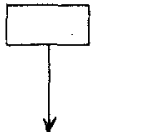

2 Children

$3 / 4$ time job

C

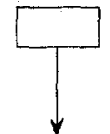

3 Children

Full time job

D

IL 7

(Go to Q. )

nterviewer: If $B$ or $C$, ask: Which of the fol-

lowing would be your next choice? Read aloud

the two choices. Check appropriate box below

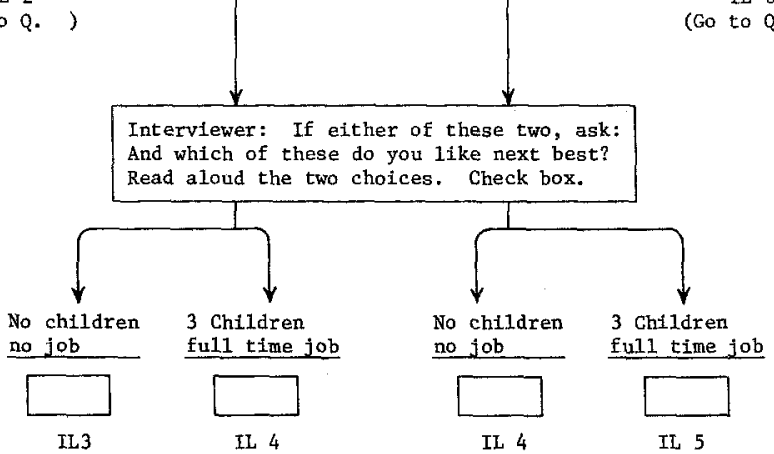

* For males.

The IL" under the last box checked is the Involvenent Level Scale number to be coded.

FIGURE 5. Illustrative Cards for Use with Scale Protocols.

primary objective. Pretesting indicated little problem in the field, however, and most of the interviews have now been carried out. The protocols were simple to administer, taking less than five minutes of interview time. Preliminary data indicate that over 90 percent completed the scale questions. 


\section{DISCUSSION}

One issue that is always raised about subjective variables is their validity. While predictive validity must depend on substantive research of longitudinal design, the validity of the measurement model and the variables derived therefrom is directly addressed by this methodological study and the evidence for it is quite good. There are other points that speak directly to the validity issue. The question of whether the respondents are giving their own views as accurately as possible or whether they are reporting what they consider socially acceptable replies or saying what they think will please the interviewers (possibly more important in non-Western cultures) is frequently brought up. In this regard, the scale procedure is probably less susceptible to such maneuvering than either single global statement measures or the thermometer-type measure in which respondents self-report where they think they are on a scale with a given range. Even if a first choice is a concession to what they think the interviewer would like, this stance is difficult to maintain as successive choices are given, and most respondents would not be aware that they are being scaled or even what the relevant variables are.

Sufficient life experience to be able to envision or project themselves into the trade-off situations involved is perhaps a more serious issue for some respondents. This was probably a consideration in some of the responses from the younger undergraduates included in this report. The questions have less salience for them. The question of indifference to the issues or number of children and job involvement level, however, need not be of concern. The conjoint measurement procedure provides a direct method of detecting indifference. (See Coombs et al., 1975 , p. 293 for a discussion of the method of determining inessential variables.) In the 426 data sets for the two variables in the model, there were no cases in which either the involvement level or the job vs. child orientation variable was inessential. That is, there was not even one instance of indifference on either issue. It obviously is a topic about which people do have preferences.

In addition to the possible descriptive and predictive uses which stimulated this search for a measure of work commitment in the familial trade-off context, it has been suggested that the scales may be useful for diagnostic purposes in counseling, 
particularly for women returning for further education. Here the trade-offs may be very real, and self-knowledge of where one stands vis-à-vis others may be valuable. Underlying preferences may differ from first-blush statements or perceptions and require different strategies if goals are to be pursued realistically. For example, less than a third of the respondents who gave a first preference for two children and a full time job (a fairly heavy load) were in the job end of the JC scale (JC 1-3), and 60 percent preferred only a moderate total involvement level (IL 4-5). They might want to assess their goals carefully. A comparison of a wife's own preferences with the husband's preferences for what she does could also be very instructive.

To summarize, we find on the basis of conjoint measurement analysis that there are two crucial variables on preferences in the work-child domain, a total level of involvement and a job vs. child orientation. Using unfolding theory, a scale ranging from 1 to 7 is developed for each dimension. The Total Involvement Level Scale ranges from a preference for least involvement (IL 1) to a preference for the most involvement (IL 7). The Job vs. Child Orientation Scale ranges from greatest job commitment or orientation (JC 1) to greatest child orientation (JC 7). As the two scales are relatively independent in a measurement sense, we can make comparisons across groups or individuals without having to stipulate what a person's level on one scale is in order to measure his level on the other. Both dimensions are probably important in the life decisions people make. The scale procedure does not tell us why an individual is at one point or another on the scale continuum; it simply measures his preference position and provides a theoretically sound tool. The correlates and consequences of such work vs. child commitment or preference must come from additional data obtained in studies of substantive interest.

\section{REFERENCES}

Axelson, L.J. The marital adjustment and marital role definitions of husbands of working and nonworking wives. Journal of Marriage and the Family, 1963, 25, 189-195.

Clarkson, F.E., Vogel, S.R., Boverman, D.M., Boverman, I.K. \& Rosenkrantz, P.S. Family size and sex role stereotypes. Science, 1970, 167, 390-392.

Coombs, C.H. A theory of data. New York: John Wiley \& Sons, 1964.

Coombs, C.H., Coombs, L.C. \& McClelland, G.H. Preference scales for number and sex of children. Population Studies, 1975, 29, 273-298.

Coombs, L.C. Are cross-cultural preference comparisons possible? A measurement- 
theoretic approach. IUSSP Paper No. 5, Liege, Belgium: International Union for the Scientific Study of Population, 1976.

Dawes, R.M. Fundamentals of attitude measurement. New York: John Wiley \& Sons, 1972.

Erskine, H. The polls: Women's roles. Public Opinion Quaterly, 1970, 34, 275-290.

Field, S. Feelings of adjustment. In F.I. Nye \& L.W. Hoffman (eds.), The employed mother in America. Chicago: Rand McNally Co., 1963.

Hall, D.T., \& Gordon, F.E. Career choices of married women: Effects on conflict, role behavior, and satisfaction. Journal of Applied Psychology, 1973, 58, 42-48.

Krantz, D.H., Luce, R.D., Suppes, P. \& Tversky, A. Foundations of measurement, Vol. 1. New York: Academic Press, 1971, 245-315.

Krantz, D.H. \& Tversky, A. Conjoint-Measurement analysis of composition rules in psychology. Psychological Review, 1971, 78, 151-169.

Mason, K.O. \& Bumpass, L U.S. women's sex-role ideology, 1970. American Journal of Sociology, 1975, 80, 1212-1219.

Mason, K.O., Czajka, J.L. \& Arber, S. Change in U.S. women's sex-role attitudes, 19641974. American Sociological Review, 1976, 41, 573-596.

Nye, F.I. Employment status of mothers and marital conflict, permanence, and happiness. Social Problems, 1959, 6, 263-266.

Orden, S.R. \& Bradburn, N.M. Working wives and marriage happiness. American Journal of Sociology, 1969, 74, 392-402.

Pratt, L. \& Whelpton, P.K. Extra-familial participation of wives in relation to interest in and liking for children, fertility and planning, and actual and desired family size. The Milbank Quarterly, 1956, 34, 44-78.

Rappaport, R. \& Rappaport, R.N. The dual career family. Human Relations, 1969, 22, 330.

Ridley, J.C. Number of children expected in relation to non-familial activities of the wife. The Milbank Quarterly, 1959, 37, 277-296.

Runkel, P.J. \& McGrath, J.E. Research in human behavior. New York: Holt, Rinehart \& Winston, 1972.

Sobol, M.G. Commitment to work. Ch. 3 in F.I. Nye \& L.W. Hoffman (eds.), The employed mother in America. Chicago: Rand McNally Co., 1963.

Sweet, J.A. Women in the labor force. New York: Seminar Press, 1973.

Vanek, J. Time spent in housework. Scientific American, 1974, 231(5), 116-120.

Weil, M.W. Factors influencing married women's actual or planned labor participation. American Sociological Review, 1961, 26, 91-96. 